This item was submitted to Loughborough's Research Repository by the author.

Items in Figshare are protected by copyright, with all rights reserved, unless otherwise indicated.

\title{
Evaluation of the high temperature performance of HfB2 UHTC particulate filled Cf/C composites
}

\section{PLEASE CITE THE PUBLISHED VERSION}

https://doi.org/10.1111/ijac.12659

\section{PUBLISHER}

Wiley ( The American Ceramic Society

VERSION

AM (Accepted Manuscript)

\section{PUBLISHER STATEMENT}

This work is made available according to the conditions of the Creative Commons Attribution-NonCommercialNoDerivatives 4.0 International (CC BY-NC-ND 4.0) licence. Full details of this licence are available at: https://creativecommons.org/licenses/by-nc-nd/4.0/

\section{LICENCE}

CC BY-NC-ND 4.0

\section{REPOSITORY RECORD}

Paul, Anish, Virtudes Rubio, J.G.P. Binner, Bala Vaidhyanathan, A. Heaton, and Peter M. Brown. 2017. "Evaluation of the High Temperature Performance of Hfb2 UHTC Particulate Filled Cf/c Composites". figshare. https://hdl.handle.net/2134/25796. 


\title{
Evaluation of the high temperature performance of $\mathrm{HfB}_{2} \mathrm{UHTC}$ particulate filled $\mathrm{C}_{\mathrm{f}} /$ Ccomposites
}

\author{
Anish Paul ${ }^{1, \dagger}$ (D) | Virtudes Rubio ${ }^{1}$ Jon Binner ${ }^{1}$ | Bala Vaidhyanathan ${ }^{2} \mid$ Andrew Heaton ${ }^{3}$ | \\ Peter Brown ${ }^{3}$
}

${ }^{1}$ School of Metallurgy and Materials, University of Birmingham, Birmingham, UK

${ }^{2}$ Department of Materials, Loughborough University, Loughborough, UK

${ }^{3}$ Dstl, Porton Down, Salisbury, UK

Correspondence

Anish Paul

Email: anish.paul@ansaldoenergia.com

Present address

${ }^{\dagger}$ Ansaldo Energia Switzerland AG, Baden, Switzerland.

Funding information

UK's Defence Science and Technology

Laboratory, Grant/Award Number:

DSTLX-1000015267

\begin{abstract}
Room and high temperature flexural strength and coefficient of thermal expansion (CTE) of $\mathrm{HfB}_{2}$ ultra-high temperature ceramic (UHTC) particulate filled $\mathrm{C}_{\mathrm{f}} / \mathrm{C}$ composites are determined along with UHT oxidation behavior. Both room and high temperature strength of the composites were found to be broadly comparable to those of other thermal protection system materials currently being investigated. The CTE of the composites was measured both along and perpendicular to the fiber direction up to $1700^{\circ} \mathrm{C}$ and the values were found to depend on fiber orientation by approximately a factor of 3. Arc-jet testing of the UHTC composites highlighted the excellent ultra-high temperature oxidation performance of these materials.
\end{abstract}

\section{KEYWO R DS}

borides, ceramic matrix composites, oxidation resistance

\section{1 | INTRODUCTION}

Ultra-high temperature ceramics (UHTCs) are candidate materials for use as leading edges, control surfaces, engine inlets and exits, and engine hot flow path components in hypersonic vehicles. In recent years, these materials have been extensively investigated as innovative thermal protection systems (TPS) $)^{1-3}$ and sharp leading edge components ${ }^{4-6}$ for aerospace vehicles as well as for other applications where oxidation and/or erosion resistance at temperatures up to and exceeding $2000^{\circ} \mathrm{C}$ are required. The main materials that are being researched as UHTCs are the borides and carbides of transition metals, eg $\mathrm{HfB}_{2}, \mathrm{ZrB}_{2}$, HfC, and $\mathrm{ZrC}$. They are refractory in nature and have melting temperatures above $3000^{\circ} \mathrm{C}^{7-9}$ The suitability of single phase ceramics is significantly limited, however, due to their poor thermal shock and oxidation resistance. ${ }^{10}$ Even with the addition of a second or third ceramic phase, such as $\mathrm{SiC}$ or $\mathrm{LaB}_{6}$, these materials do not possess the high temperature resistance, thermal shock resistance, or fracture toughness required. ${ }^{11}$ This clearly highlights the need to adopt a fiber reinforced composite approach. Carbon fiber (Cf) and silicon carbide fiber ( $\mathrm{SiCf}$ ) are two obvious choices, provided they can be protected at the application temperatures.

There are a number of reports in the literature about the preparation of continuous fiber reinforced UHTC composites using $\mathrm{SiC}^{4,12,13}$ and $\mathrm{C}$ fibers. ${ }^{14-30}$ Processing methodologies adopted for the preparation of UHTC composites include precursor infiltration and pyrolysis, ${ }^{18-21}$ chemical vapor deposition, ${ }^{22-24}$ reactive melt infiltration, ${ }^{25,26}$ slurry infiltration and pyrolysis, ${ }^{14-17}$ or a combination of processes. ${ }^{27-29} \mathrm{~A}$ number of groups dedicated their efforts to prepare short fiber reinforced composites, ${ }^{30-35}$ the advantage being the ability to apply the processing techniques developed for monolithic UHTC materials. However, the improvement in mechanical properties, especially toughness, achieved with the latter class of materials was not significant.

Previous studies conducted by the present authors ${ }^{16}$ compared the high temperature oxidation performance of a variety of Cf-based UHTC composites viz., Cf-ZrB 2 , Cf-ZrB $2-$ 20 vol\% SiC, Cf-ZrB $2-20$ vol\% SiC-10 vol\% LaB6, Cf$\mathrm{HfB}_{2}$, and Cf-HfC, using an oxyacetylene flame and reported that the best performance was observed for Cf- 
$\mathrm{HfB}_{2}$. The main focus of the present study was to determine the room and high temperature flexural strength of these UHTC composites together with the coefficient of thermal expansion (CTE) along and across the fiber direction. Ultrahigh temperature oxidation tests were carried out using an arc-jet facility, which is considered as the best ground based testing technique for evaluating high temperature oxidation performance. Arc-jets provide conditions that are similar to the aero-thermal environment experienced during flight and hence the results are used to understand the thermal performance of materials and systems under controlled aero-thermal heating conditions. The results have been used to validate the numerical models of materials and systems that are used as design tools. ${ }^{5}$ Nevertheless, there are a number of differences between arc-jet and flight environments that must be accounted for when interpreting the data. For example, surface catalycity can play a more significant role during arc-jet testing than in re-entry, because a higher proportion of the air molecules are dissociated in the former environment. ${ }^{36}$ Detailed microstructural characterization was carried out on the post test samples and conclusions drawn about the advantages of incorporating UHTC particles on high temperature performance.

\section{EXPERIMENTAL}

\subsection{Preparation of $\mathrm{HfB}_{2}$ UHTC particulate filled composites}

The composites used in the current study were prepared utilizing a slurry composed of $\mathrm{HfB}_{2}$ (325 mesh, HC Starck, Karlsruhe, Germany), acetone, and phenolic resin (Cellobond J2027L, Hexion Specialty Chemicals, B. V., Rotterdam, the Netherlands). The ingredients were mixed in the required ratio, a typical formulation contained $40 \mathrm{~g} \mathrm{HfB}_{2}$, $20 \mathrm{~g}$ phenolic resin and $12.5 \mathrm{~g}$ acetone, and ball milled for 48 hours to achieve a slurry with the required consistency ( $\sim 10 \mathrm{mPa}$ seconds at $100 \mathrm{~s}^{-1}$ shear rate). Cf preforms with 2.5D structure were obtained from Surface Transforms (Surface Transforms plc., Cheshire, UK). Cf Preforms which measure about $180930915 \mathrm{~mm}$ were used for preparing UHTC composites for flexural strength and CTE measurements; $52 \mathrm{~mm}$ diameter by $\sim 20 \mathrm{~mm}$ thick preforms were used for arc-jet samples. Impregnation of the preforms was carried out using a vacuum-assisted technique where the preform was fully submerged in the UHTC slurry contained in a vacuum chamber. The chamber was then evacuated with a vacuum pump to facilitate the impregnation of the slurry. Further details on the composite processing can be found elsewhere. ${ }^{16}$ Final densification was achieved using five cycles of chemical vapor infiltration (CVI) of carbon at Surface Transforms plc. After CVI densification, flexural strength $(140925910 \mathrm{~mm})$ and CTE
(109595 mm) specimens were machined out from the larger composites. CTE specimens were machined such that measurements could be made both along and perpendicular to the fiber direction. Arc-jet specimens were machined down to final dimensions of $30 \mathrm{~mm}$ diameter95 mm thickness, so that they could be mounted in a carbon-carbon (CC) composite sample holder. $\mathrm{C}_{\mathrm{f}} / \mathrm{C}$ composites for comparative measurements were prepared by CVI densification of $2.5 \mathrm{D}$ carbon fiber preforms at Surface Transforms, without any powder impregnation. The bulk density of $\mathrm{HfB}_{2}$ particulate filled $\mathrm{C}_{\mathrm{f}} / \mathrm{C}$ composites and $\mathrm{C}_{\mathrm{f}} / \mathrm{C}$ composites were $2.2 \pm 0.14$ and $1.8 \pm 0.04 \mathrm{~g} \mathrm{~cm}^{-3}$, respectively. The final porosity of all the composites was around $10 \%$.

\section{2 | Flexural strength and CTE measurements}

Room temperature (RT) and high temperature (HT) 4-point flexural strength measurements were carried out at CERAM $^{1}$ (Stoke-on-Trent, Staffordshire, UK) according to Documented In-House Methods R102:1990 and R101:2002, respectively. The test setup was calibrated before testing began and the deflection measurements were initiated after the test temperatures were reached to minimize the influence of the thermal expansion of the extensometer. RT strength measurements were conducted in air whereas HT strength measurements were carried out under a flowing argon atmosphere. The strength of the composites was determined using large, $140925910 \mathrm{~mm}$, samples; this was essential to give a true representation of the UHTC composite because of its graded structure. As per the specification, prior to HT testing, the composites were coated with a commercial product known as Tipp-Ex (a slurry of $\mathrm{TiO}_{2}$ in an organic medium intended for use as a paper correction fluid) all over the surface, except where it came in contact with the loading and support rollers, to minimize any oxidation due to the presence of residual oxygen. A $5 \mathrm{~N}$ preload was applied to ensure proper contact between the sample and the rollers. The test rig used for HT testing, along with a Tipp-Ex coated test bar, is shown in Figure 1. The HT test parameters are summarized in Table 1. RT test parameters were similar except the fact that there was no heating or gas flow.

The argon flow rate employed was sufficient, in theory, to replace the atmosphere within the box furnace approximately four times every minute; this involved a flow rate of $15 \mathrm{~L} \mathrm{~min}{ }^{-1}$. Presence of residual oxygen is expected as the furnace employed is not a sealed system. The hold duration at $1400^{\circ} \mathrm{C}$ was limited to 5 minutes to minimize any oxidation at high temperature due to the presence of residual oxygen.

${ }^{1}$ Now Lucideon Ltd. 


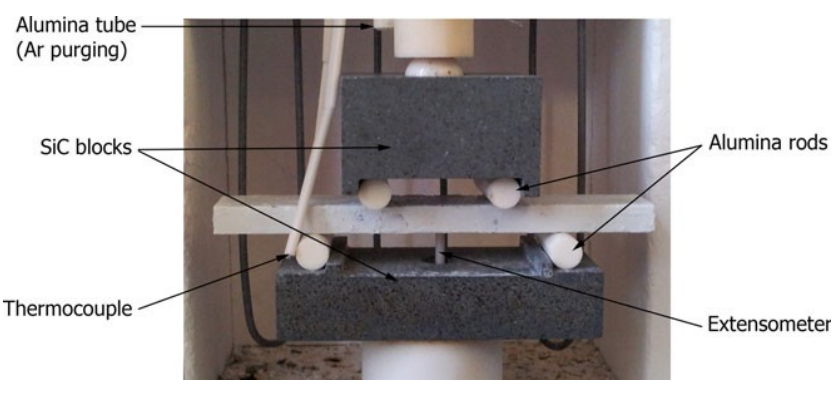

FIGU RE 1 4-point bend test rig at CERAM. A test bar coated with Tipp-Ex ${ }^{\circledR}$ can also be seen [Color figure can be viewed at wileyonlinelibrary.com]

TABLE 1 HT 4-point bend test parameters used at CERAM

\begin{tabular}{lc} 
Parameter & Value \\
Test temperature, ${ }^{\circ} \mathrm{C}$ & 1400 \\
Heating rate, ${ }^{\circ} \mathrm{C}$ min $^{-1}$ & 50 \\
\hline Hold duration at $1400^{\circ} \mathrm{C} \mathrm{min}$ & -1 \\
Argon flow rate, $\mathrm{L} \mathrm{min}^{-1}$ & 5 \\
Initial load, $\mathrm{N}$ & 15 \\
Cross-head speed, $\mathrm{mm} \mathrm{min}^{-1}$ & 5 \\
Support span, $\mathrm{mm}$ & 0.5 \\
Loading span, $\mathrm{mm}$ & 80 \\
\hline
\end{tabular}

The CTE was measured at Imperial College London, UK, according to ASTM E831, using a Netzsch 402C dilatometer (Netzsch-Geratebau GmbH, Selb, Germany) with a graphite sample holder and pushrod. Samples were heated at $10^{\circ} \mathrm{C} \mathrm{min}{ }^{-1}$ from room temperature to $1700^{\circ} \mathrm{C}$ under helium atmosphere while recording the displacement of the pushrod. By calibrating the expansion of the set-up with a graphite sample of known thermal expansion, the displacement of the pushrod was converted in actual thermal expansion data for the sample. Since the pushrod exerted a force of $\sim 1.5 \mathrm{~N}$ on the sample to ensure that good contact was maintained, data collected at the highest temperatures should be treated with caution as compressive creep might have counter-acted the thermal expansion of the sample. Specimens were prepared, so that the CTE values could be measured both along and across the fiber directions.

It is customary to describe the thermal expansion using Equation 1.

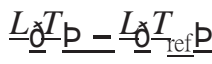

$$
\begin{aligned}
& L ð T_{\text {ref }} \mathrm{P} \quad 1 / 4 \mathrm{a}_{\mathrm{avg}} \cdot \mathrm{DT}
\end{aligned}
$$

where $a_{a v g}$ is the average coefficient of thermal expansion from $T_{\text {ref }}$ to $T ; L(T)$ is the length of sample at temperature $T ; L\left(T_{\text {ref }}\right)$ is the length of sample at reference temperature $T_{\text {ref; }}$ DT $=T-T_{\text {ref. }}$.
TABLE 2 Arc-jet test parameters

\begin{tabular}{lcc} 
Parameter & Value \\
Sample & AJ5-20 & AJ10-10 \\
Test duration, s & 20.1 & 10.6 \\
Heat flux, MW m & & 10.1 \\
Distance from the nozzle exit, mm & 160 & 100 \\
Peak measured temperature, ${ }^{\circ} \mathrm{C}$ & 2400 & 2650 \\
Specific gas enthalpy, $\mathrm{MJ} \mathrm{kg}^{-1}$ & \multicolumn{2}{c}{15.9} \\
Nozzle configuration & 50 mm exit diameter \\
Test gas or atmosphere & \multicolumn{2}{c}{ Air } \\
\hline
\end{tabular}

\section{3 | Arc-jet testing}

Arc-jet tests of the samples were carried out at the German Aerospace Centre (Deutsches Zentrum fur Laft- und Raumfahrt, DLR, Cologne, Germany). One UHTC sample (AJ5-20) was tested at a heat flux of $5 \mathrm{MW} \mathrm{m}^{-2}$ for $\sim 20$ seconds whereas a second sample (AJ10-10) was tested at $10 \mathrm{MW} \mathrm{m}^{-2}$ for $\sim 10$ seconds. The test parameters are summarized in Table 2. The front face temperature during testing was measured using a two color pyrometer (Dr. Maurer QKTR1485, Dr. Georg Maurer GmbHOptoelektronik, Germany) calibrated from 900 to $3000^{\circ} \mathrm{C}$ and a spectral pyrometer (Dr. Maurer KTR1485-Z, Dr. Georg Maurer GmbH-Optoelektronik, Germany), sensitive at $11 \mathrm{~m}$ and calibrated between 900 and $3000^{\circ} \mathrm{C}$.

The surface and cross-sectional microstructures and chemical compositions of the arc-jet samples were studied using field emission gun scanning electron microscopy (FEGSEM, Leo 1530VP, LEO, Elektronenskopie GmbH, Oberkochen, Germany) and energy dispersive spectroscopy (EDS, EDAX Inc., Mahwah, NJ).

\section{3 | RESULTS AND DISCUSSION}

\section{1 | Flexural strength measurement}

The stress-strain curves for the $\mathrm{C}_{\mathrm{f}} / \mathrm{C}$ and $\mathrm{HfB}_{2}$ UHTC particulate filled $\mathrm{C}_{\mathrm{f}} / \mathrm{C}$ composites after $\mathrm{RT}$ and $\mathrm{HT}$ testing are given in Figure 2 and Table 3 summarizes the flexural strength data. The alumina rollers failed on at least three occasions during the HT testing, resulting in step changes in the stress-strain curves. This can be identified from the stress-strain plots of UHTC-HT5, CC-HT1, and CC-HT2. One of these samples (CC-HT1) was retested and it yielded a much lower strength of $85.01 \mathrm{MPa}$. All other composites deformed and did not show any sign of obvious failure. The Tipp-Ex applied on the surface formed a pale yellow substance, which was identified to be mainly $\mathrm{TiO}_{2}$. A white layer on the surface of the UHTC composite after HT 

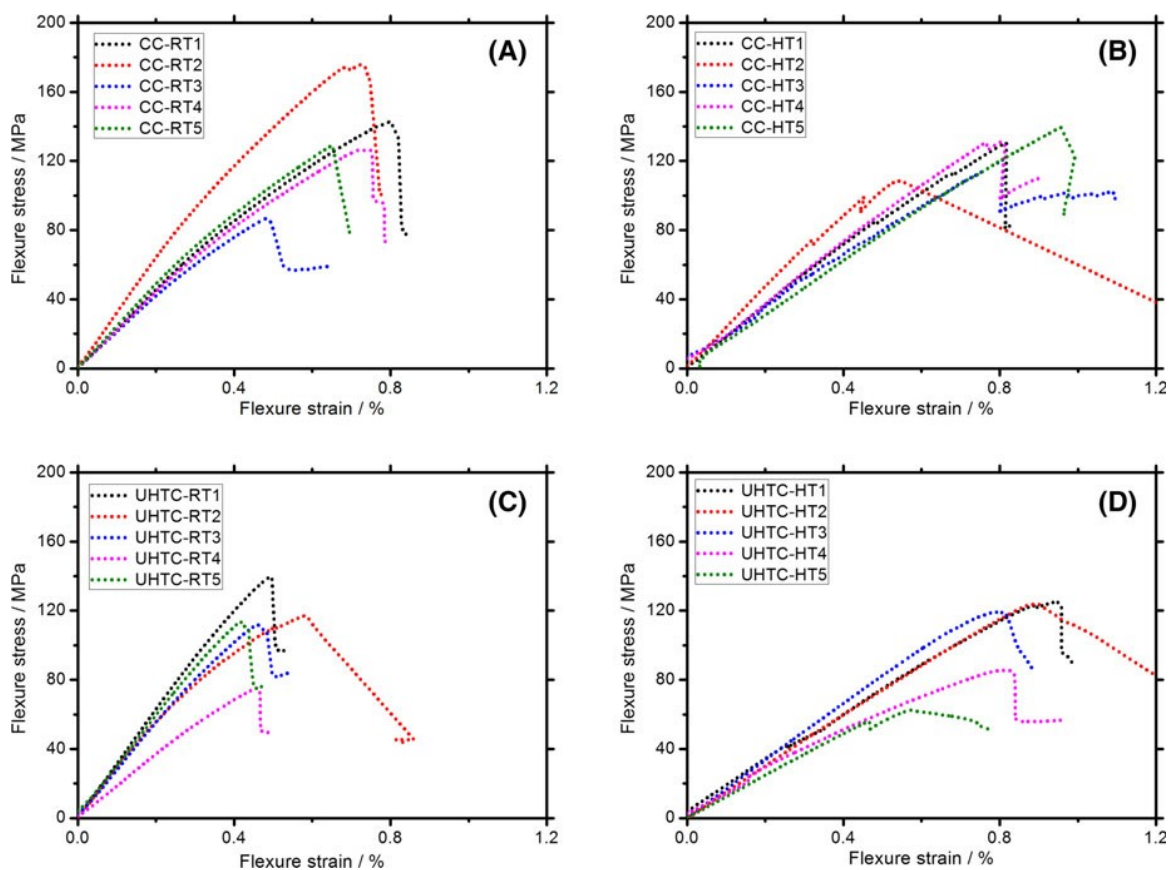

FIGU RE 2 Stress-strain curves after flexural strength testing. (A) CC at RT, (B) CC at HT, (C) UHTC at RT, and (D) UHTC at HT

TABLE 3 RT and HT strength of UHTC and CC composites

\begin{tabular}{|c|c|c|c|c|c|c|c|}
\hline \multicolumn{4}{|c|}{ UHTC composites } & \multicolumn{4}{|c|}{ CC composites } \\
\hline \multicolumn{2}{|l|}{$\mathrm{RT}$} & \multirow{2}{*}{$\begin{array}{l}\text { HT } \\
\text { Sample }\end{array}$} & \multirow[b]{2}{*}{ Max. Str, $\mathrm{MPa}$} & \multirow{2}{*}{$\begin{array}{l}\text { RT } \\
\text { Sample }\end{array}$} & \multirow[b]{2}{*}{ Max. Str, MPa } & \multicolumn{2}{|l|}{$\mathrm{HT}$} \\
\hline Sample & Max. Str, MPa & & & & & Sample & Max. Str, MPa \\
\hline UHTC-RT1 & 139.69 & UHTC-HT1 & 124.96 & CC-RT1 & 142.70 & CC-HT1 & $130.97^{\mathrm{a}}$ \\
\hline UHTC-RT2 & 116.98 & UHTC-HT2 & 124.10 & CC-RT2 & 175.59 & CC-HT2 & $108.64^{\mathrm{a}}$ \\
\hline UHTC-RT3 & 111.84 & UHTC-HT3 & 119.32 & CC-RT3 & 86.97 & CC-HT3 & 120.88 \\
\hline UHTC-RT4 & 75.23 & UHTC-HT4 & 85.51 & CC-RT4 & 126.41 & CC-HT4 & 131.26 \\
\hline UHTC-RT5 & 113.54 & UHTC-HT5 & $62.67^{\mathrm{a}}$ & CC-RT5 & 129.15 & CC-HT5 & 139.45 \\
\hline
\end{tabular}

RT, room temperature; HT, high temperature; UHTC, ultra-high temperature ceramic; CC, carbon-carbon.

andicates the failure of the alumina rollers during testing.

strength testing was characterized using EDS (data not shown) and found to be $\mathrm{HfO}_{2}$. The oxidation of the TippEx and $\mathrm{HfB}_{2}$ confirmed the presence of residual oxygen at the test temperature.

The $\mathrm{C}_{\mathrm{f}} / \mathrm{C}$ composites displayed a higher deformation at room temperature compared to the UHTC composites. No brittle failure was observed at RT or HT, but rather a small amount of deformation was observed. $\mathrm{C}_{\mathrm{f}} / \mathrm{C}$ composites were also coated with Tipp-EX prior to testing, but it fell off completely during the test, possibly due to the degradation of the surface carbon fibers. There was negligible mass change for the UHTC composites after HT testing, but the $\mathrm{C}_{\mathrm{f}} / \mathrm{C}$ composites had $\sim 12 \%$ mass loss indicating oxidation of the test bars at elevated temperatures.

The average RT strength of UHTC composites was $111 \pm 20 \mathrm{MPa}$ and that of $\mathrm{C}_{\mathrm{f}} / \mathrm{C}$ composites was
$132 \pm 28 \mathrm{MPa}$. The average HT strength of UHTC composites was $103 \pm 25 \mathrm{MPa}$ and that of $\mathrm{C}_{\mathrm{f}} / \mathrm{C}$ composites was $126 \pm 0 \mathrm{MPa}$. The RT strength values reported in the literature for UHTC composites include $107 \mathrm{MPa}^{19}$ or $150-170$ $\mathrm{MPa}^{12}$ for Cf-ZrC; $237 \mathrm{MPa}$ for $\mathrm{Cf} / \mathrm{ZrB}_{2}-\mathrm{SiC}^{28} 25 \mathrm{MPa}$ for $\mathrm{Cf}-\mathrm{HfC}^{22}$ and $\sim 100$ or $162 \mathrm{MPa}$ for a functionally graded $\mathrm{Cf} / \mathrm{HfB}_{2}-\mathrm{SiC}$ composite, ${ }^{37}$ the latter values depending on whether the $\mathrm{SiC}$ or $\mathrm{HfB}_{2}$ side was in tension. It is not valid to make direct comparisons as the properties of a composite depend on the fiber volume fraction, fiber surface treatment, fiber orientation, amount of porosity, type of carbon deposit, processing temperature, and the type and amount of fillers.

Considering the error bars, it is reasonable to conclude that there was no decrease in the average strength of the UHTC and $\mathrm{C}_{\mathrm{f}} / \mathrm{C}$ composites at $1400^{\circ} \mathrm{C}$, though it is 
difficult to make any statistical conclusions because of the failure of the rollers in some instances and the partial oxidation of the composites. $\mathrm{C}_{\mathrm{f}} / \mathrm{C}$ composites showed a slightly higher strength compared to UHTC composites at both room and high temperature. This is not that surprising as the addition of UHTC powder was expected to reduce the overall strength of the composites by forcing apart the tows slightly as the UHTC powder penetrated.

The difficulties associated with the failure of the support rollers at high temperature along with a need for improved atmosphere control need to be addressed in the future to improve the accuracy of measurements.

\section{2 | CTE measurements}

The change in length of the samples with temperature for the UHTC and $\mathrm{C}_{\mathrm{f}} / \mathrm{C}$ composites from the initial heating is shown in Figure 3A. All samples showed a large expansion around $1000^{\circ} \mathrm{C}$, followed by shrinkage around $1250^{\circ} \mathrm{C}$. In one case, the shrinkage was so strong that after cooling, a permanent shrinkage of about $501 \mathrm{~m}$ on a $10 \mathrm{~mm}$ sample was recorded. As this variation was also observed for the $\mathrm{C}_{\mathrm{f}} / \mathrm{C}$ samples, it is assumed that the carbon fibers were allowing the CVI-deposited carbon and/or $\mathrm{HfB}_{2}$ powder to undergo some rearrangement at this temperature. It has been reported that for carbon materials, the thermal expansion in any direction is equal to the sum of crystallite expansions resolved in that direction but a proportion of that is accommodated by internal adjustments. The degree of accommodation is primarily dependent on the preferred orientation of the crystallites with a secondary dependence on the apparent density of carbon. The presence of submicroscopic porosity is responsible for this secondary dependence, ${ }^{37}$ the $\mathrm{C}_{\mathrm{f}} / \mathrm{C}$ and UHTC composites in the present study had a porosity of around $10 \%$. It is also worth noting that the rapid change in dimensions was observed above the temperature employed for CVI of carbon, the highest seen by the sample during processing, prior to CTE measurements. This also suggested that the processing temperature may not have been sufficient to produce materials that were stable at high temperatures. As a result of these variations, a second round of measurements was also carried out for the same samples and the results are shown in Figure 3B. This run produced rather smooth curves without much change in slope and the average CTE values from these measurements are summarized in Table 4.

The average CTE values of the UHTC composites were found to be $1.63 \pm 0.13910^{-6 \circ} \mathrm{C}^{-1}$ and $4.67 \pm 0.219$ $10^{-6 \circ} \mathrm{C}^{-1}$, respectively, along and across the ply. The corresponding values for the $\mathrm{C}_{\mathrm{f}} / \mathrm{C}$ composites were 2.83

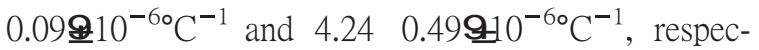

tively. Type of fiber, type of matrix, bonding between the fiber and matrix, volume fraction of the fiber and inter-ply angle are all factors that could influence the CTE values. The CTE of $\mathrm{Cf}$ along the axis is reported to be negligible $\left(\sim 0910^{-6 \circ} \mathrm{C}^{-1}\right)$ compared to the value in the radial direction $\left(\sim 8910^{-6 \circ} \mathrm{C}^{-1}\right) .{ }^{38}$ Polymer-derived carbon has a CTE of $2-4910^{-6 \circ} \mathrm{C}^{-1}$ and pyrolytic carbon, which is isotropic, has a CTE value in the range $4-6910^{-60} \mathrm{C}^{-1} .{ }^{39}$ The CTE of $\mathrm{HfB}_{2}$ is reported to be $6.3-7.6910^{-60} \mathrm{C}^{-1}$. ${ }^{36}$ So it can be assumed that the lower CTE of $\mathrm{C}_{\mathrm{f}} / \mathrm{C}$ and UHTC composites along the ply are mainly due to the lower CTE of $\mathrm{Cf}$ along the axial direction. The contribution of each constituent phase to the final CTE can be estimated provided the mass fraction of each of the constituents, ie Cf, polymer-derived carbon (from the phenolic resin), pyrolytic carbon (from CVI), $\mathrm{HfB}_{2}$ and submicroscopic porosity are known along with the integrity of the bond between the fiber and matrix.

TABLE 4 Coefficient of thermal expansion values of $\mathrm{CC}$ and UHTC composites

$\begin{array}{ll}\text { Material } & \mathrm{a}_{\mathrm{avg}} 310^{6{ }^{\circ}} \mathrm{C}^{-1}\left(25-1700^{\circ} \mathrm{C}\right) \\ \mathrm{Cf}-\mathrm{HfB}_{2} \text { along the ply } & 1.63 \pm 0.13 \\ \mathrm{Cf}-\mathrm{HfB}_{2} \text { across the ply } & 4.67 \pm 0.21 \\ \mathrm{CC} \text { along the ply } & 2.83 \pm 0.09 \\ \mathrm{CC} \text { across the ply } & 4.24 \pm 0.49\end{array}$

CC, carbon-carbon; UHTC, ultra-high temperature ceramic.
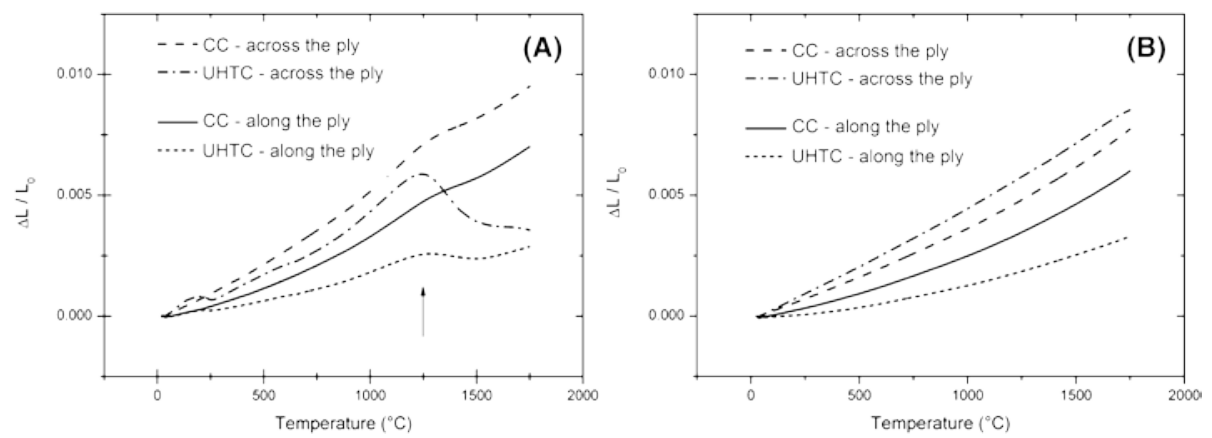

FIGU RE 3 Change in length with temperature for CC and UHTC composites. (A) Initial run and (B) repeated run 
The variation in CTE values along and across the fiber direction needs careful consideration while designing TPS components using UHTC composites. This variation can also be used as a design tool to fabricate UHTC composites with tailored CTE values.

\subsection{Arc-jet testing of $\mathrm{HfB}_{2}$ UHTC particulate filled composites}

Figure 4 shows one of the $\mathrm{Cf}-\mathrm{HfB}_{2}$ samples being tested, whilst the time-temperature profiles during testing are given in Figure 5. Figure 6 compares the images of the composites before and after the test. AJ5-20 has seen a peak temperature of $-2500^{\circ} \mathrm{C}$ whereas the sample tested at the higher heat flux, AJ10-10 reached around $2700^{\circ} \mathrm{C}$. Melting of the UHTC phase was not observed at $5 \mathrm{MW} \mathrm{m}^{-2}$, whereas melting was observed at $10 \mathrm{MW} \mathrm{m}^{-2}$ indicating that the actual temperature experienced by the sample may have been higher than the measured value (melting point of $\left.\mathrm{HfO}_{2} \sim 2900^{\circ} \mathrm{C}\right){ }^{40}$ The oxide layer formed on AJ5-20 was uniform whereas the higher velocity jet removed some of the molten materials from the surface of AJ10-10 during the test. Both samples survived the rapid heating and maintained their integrity indicating their ability to withstand ultra-high temperatures and thermal shocks. Combining this with their lower density, UHTC composites have an advantage over UHTC monoliths for UHT applications.

Figure 7 shows the surface microstructure of AJ5-20 after testing. The surface of the sample indicated the presence of defects, Figure 7A. Necking of the particles was observed, as shown in Figure 7B. Figure 7C shows an area near the edge of the sample, where the surface layer became delaminated during the test. This delamination may have been caused by defects generated during the machining of the composite to the required dimensions, causing the fibers underneath the surface layer to be exposed to the jet. The carbon fibers underwent severe degradation and

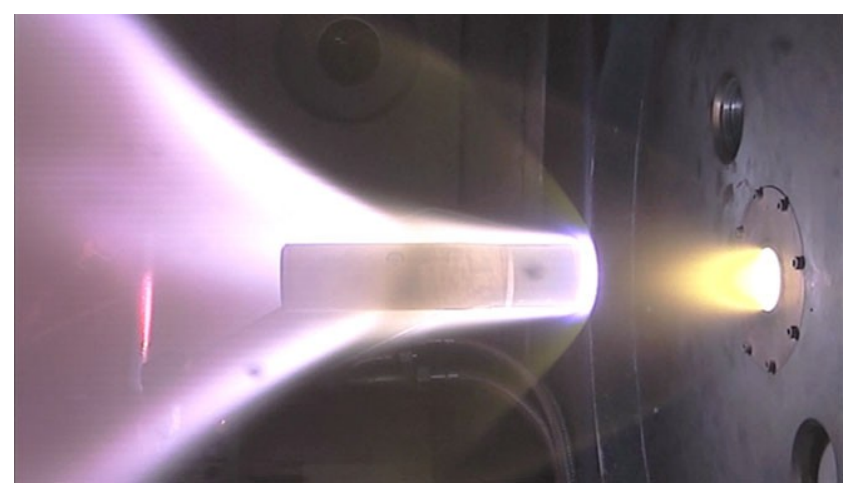

FIGU RE 4 A picture of one of the samples being arc-jet tested, showing the demanding nature of the test [Color figure can be viewed at wileyonlinelibrary.com] the UHTC particles showed partial oxidation; they were not exposed to the jet for long enough to undergo complete oxidation, Figure 7D. Similar partial oxidation behavior was reported for $\mathrm{TaC}$ during high temperature testing. ${ }^{41,42}$

AJ10-10 sample experienced a higher temperature and heat flux compared to AJ5-20, but the test duration was shorter. The oxide particles were melted and, on solidification, formed a dense layer as shown in Figure 8A. Cracks were observed in this layer. The particles also formed a protective layer for the carbon fibers, Figure 8B. An interesting observation made on the sample was the degradation and severe pitting of the carbon fibers near the edge of the composite, Figure 8C. This type of damage is believed to be due to the chemical attack on the fibers by the highly reactive gaseous species in the jet, including monoatomic oxygen. A cross-section of the sample revealed the thickness of the surface layer, which was found to be $\sim 451 \mathrm{~m}$, Figure 8D. The surface cracks observed in Figure 8A were not propagated to the bulk of the composite, offering protection for the underlying carbon fibers.

In a previous study, ${ }^{5}$ arc-jet testing has been used on monolithic $\mathrm{HfB}_{2}-20$ vol\% SiC ceramics for much longer
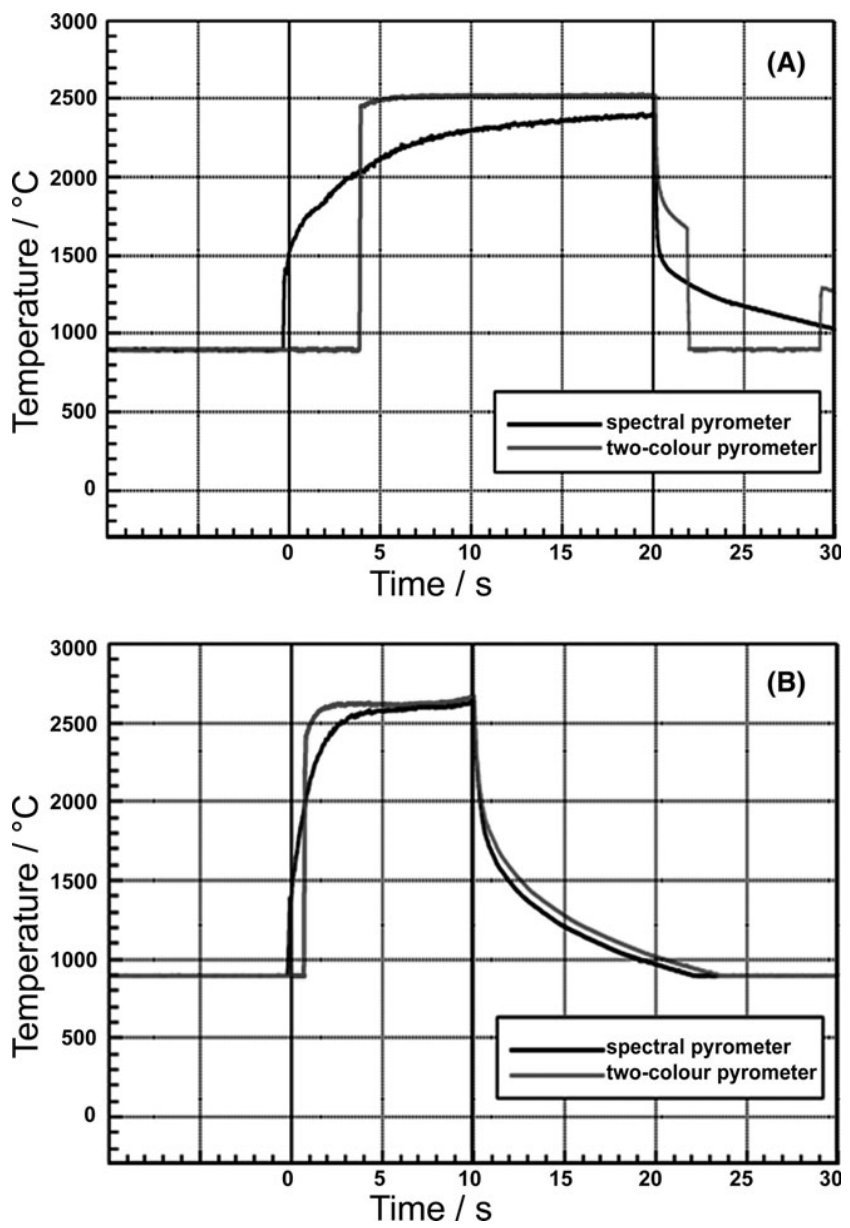

FIGURE 5 Time-temperature profile during the arc-jet testing of UHTC composites. (A) AJ5-20 and (B) AJ10-10 


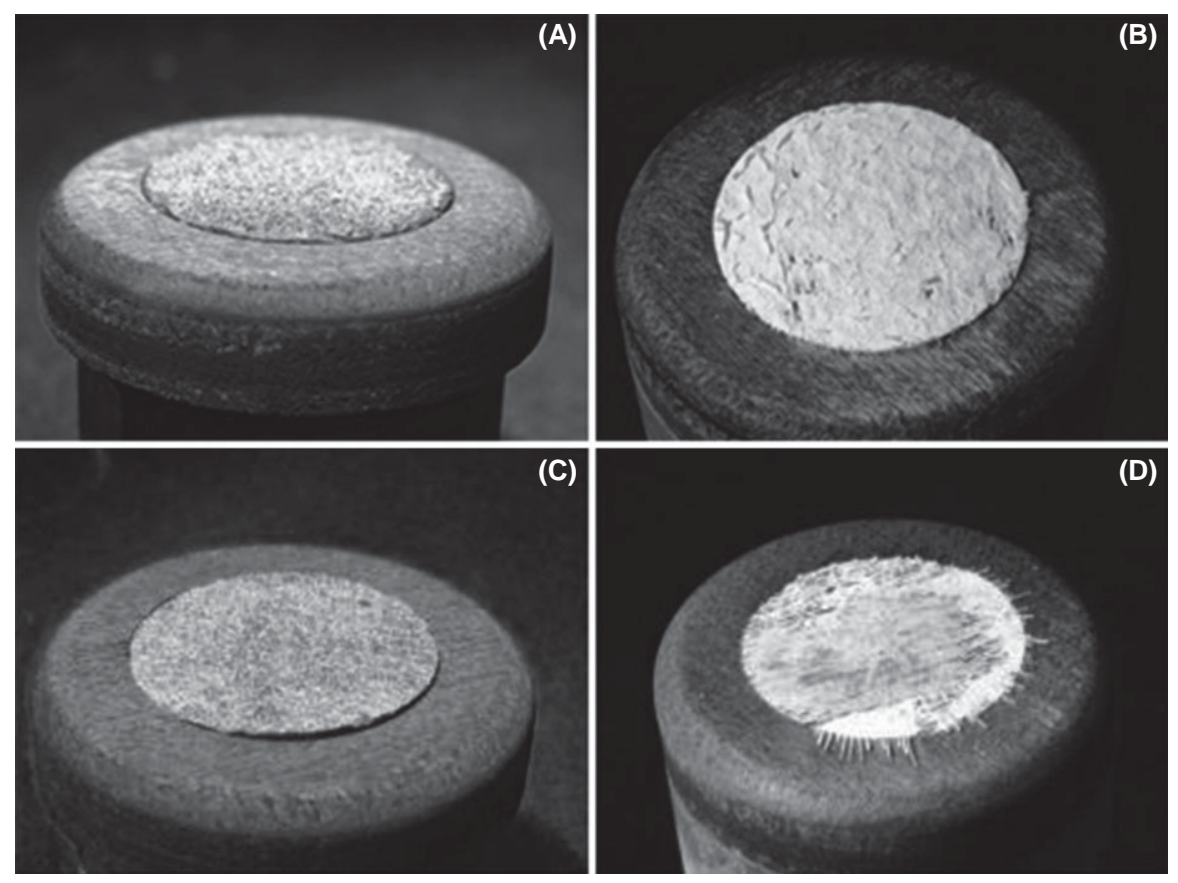

FIGU RE 6 Ultra-high temperature ceramic composites before and after arc-jet testing. (A) AJ5-20 before test, (B) AJ5-20 after test, (C) AJ10-10 before test, and (D) AJ10-10 after test
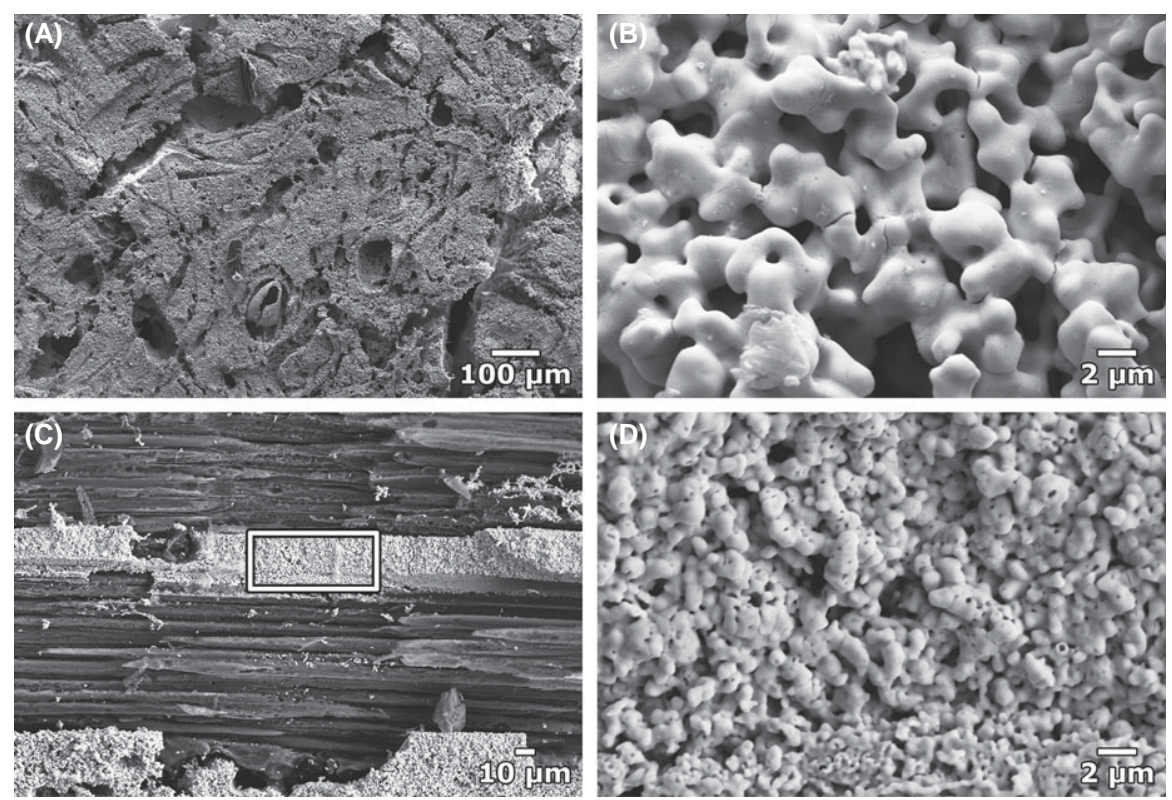

FIGU RE 7 Surface microstructure of AJ5-20 after arc-jet testing. (A) Surface of the sample, (B) higher magnification image showing necking of oxide particles, $(C)$ is an area where the fibers were exposed to the jet, and (D) is a higher magnification image of the highlighted area showing partial oxidation of ultra-high temperature ceramic particles

durations than in the current work but also at much lower heat fluxes, 20 minutes at $285-350 \mathrm{~W} \mathrm{~cm}^{-2}$, and showed the formation of a thick, $\sim 3401 \mathrm{~m}$, and highly porous oxide layer, due to $\mathrm{SiO}_{2}$ removal. The porous channels formed helped oxygen to diffuse through the material, yielding a $\mathrm{SiC}$ depletion layer around $\sim 740 \mathrm{~lm}$ thick below the oxide layer.
Pressureless sintered monolithic $\mathrm{HfB}_{2}$ and $\mathrm{HfC}$, both containing 5 vol\% $\mathrm{MoSi}_{2}$, have also been arc-jet tested, ${ }^{43}$ the stagnation point heat flux was $5-8 \mathrm{MW} \mathrm{m}^{-2}$ for the $\mathrm{HfB}_{2}-\mathrm{MoSi}_{2}$, which tested for 30 seconds, and $10 \mathrm{MW} \mathrm{m}^{-}$ 2 for the HfC-MoSi2, which was tested for 4 minutes. The $\mathrm{HfB}_{2}$-based sample was covered by a $15-20 \mathrm{~lm}$ silica-based layer and bubble formation was 

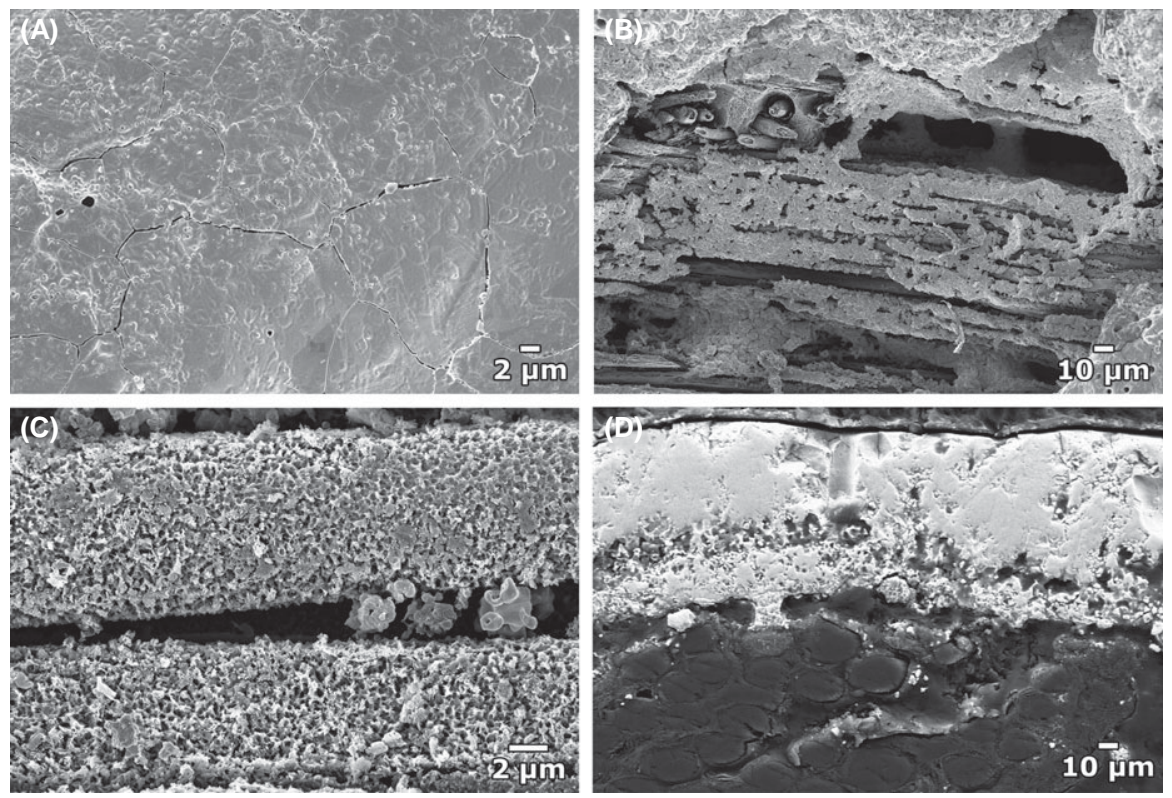

FIGU RE 8 Microstructure of AJ10-10 after arc-jet testing. (A) Microstructure formed by the melting of ultra-high temperature ceramic (UHTC) particles, (B) carbon fiber protected by the UHTC phase, (C) severe pitting of fibers near the edge of the composite, and (D) a crosssection revealing the thickness of the surface layer

observed as a result of the escape of gaseous by-products. The HfC-based sample developed a visibly cracked $\mathrm{HfO}_{2}$ layer with no glassy phase visible. A multilayered scale, -300 1m thick, partially detached from the unreacted bulk; a similar layer detachment was observed for Cf-HfC particulate composite when tested using an oxyacetylene torch. ${ }^{16}$

Severe oxidation damage has been described for $\mathrm{C}_{\mathrm{f}} / \mathrm{C}$ composites tested by arc jet, ${ }^{44}$ even at lower temperatures, since active oxidation starts at $800^{\circ} \mathrm{C}$. Oxidative consumption of the carbon fiber/carbon occurs first by transport of oxygen down cracks, leading to denuded fibers, and eventual consumption of the fibers along the cracks. This oxidation behavior is not found for $\mathrm{HfB}_{2}$ ultra-high temperature ceramic particulate $\mathrm{C}_{\mathrm{f}} / \mathrm{C}$ composite due to the protection offered by the UHTC particles. ${ }^{16}$

\section{4 | CONCLUSIONS}

The room and high temperature flexural strength and coefficient of thermal expansion of $\mathrm{HfB}_{2}$ UHTC particulate filled $\mathrm{C}_{\mathrm{f}} / \mathrm{C}$ composites have been determined and compared with those of carbon fiber-carbon composites. The $\mathrm{C}_{\mathrm{f}} / \mathrm{C}$ composites showed a slightly higher strength than the UHTC composites at both room and high temperature, but the reduction in strength at $1400^{\circ} \mathrm{C}$ was relatively small, $<10 \mathrm{MPa}$, for both groups. There are hardly any reports in the literature on the high temperature flexural strength of UHTC composites, but it can be concluded that the high temperature flexural strength of the UHTC composites from the present study is comparable to those of current generation TPS materials at this temperature.

Coefficient of thermal expansion measurements for the UHTC composites revealed a large variation along and across the ply. The CTE along the fiber direction is controlled by the CTE of the carbon fiber in the axial direction; whilst that perpendicular is controlled by the CTE of the polymer-derived carbon, pyrolytic carbon and UHTC particles.

The arc-jet test is the first of its kind reported for slurry impregnated UHTC composites. Although the test durations were short, the samples retained their shape and the surface erosion was minimal. The UHTC particles formed a protective layer at high temperature which was beneficial for the performance of the composite.

A combination of low density, good mechanical properties, defect and thermal shock resistance and high temperature oxidation resistance displayed by the $\mathrm{HfB}_{2}$ UHTC particulate filled $\mathrm{C}_{\mathrm{f}} / \mathrm{C}$ composites from this study clearly highlighted their potential for hypersonic applications. It is necessary to carry out high temperature strength measurements under a completely inert atmosphere and at even higher temperatures $\left(1700^{\circ} \mathrm{C}\right.$ or higher) to develop a better understanding of these materials at their application temperature. It is also essential to conduct arc-jet testing for longer durations.

\section{ACKNOWLEDGMENTS}

The authors thank the UK's Defence Science and Technology Laboratory (DSTL) for providing the financial support 
for this work under contract number DSTLX-1000015267. Dr. Luc Vandeperre is thanked for his help with measuring CTE at Imperial College, London.

\section{REFERENCES}

1. Opeka MM, Talmy IG, Zaykoski JA. Oxidation-based materials selection for $2000 \mathrm{C}+$ hypersonic aerosurfaces: theoretical considerations and historical experience. J Mater Sci. 2004;39:58875904.

2. Chamberlain AL, Fahrenholtz WG, Hilmas GE, Ellerby DT. Characterization of zirconium diboride for thermal protection systems. Key Eng Mater. 2004;264:493-496.

3. Savino R, De Stefano Fumo M, Paterna D, Serpico M. Aerothermodynamic study of UHTC-based thermal protection systems. Aerosp Sci Technol. 2005;9:151-160.

4. Levine SR, Opila EJ, Halbig MC, Kiser JD, Singh M, Salem JA. Evaluation of ultra-high temperature ceramics for aeropropulsion use. J Eur Ceram Soc. 2002;22:2757-2767.

5. Gasch M, Ellerby D, Irby E, Beckman S, Gusman M, Johnson S. Processing, properties and arc jet oxidation of hafnium diboride/ silicon carbide ultra high temperature ceramics. J Mater Sci. 2004;39:5925-5937.

6. Zhang X, Hu P, Han J, Meng S. Ablation behavior of $\mathrm{ZrB}_{2}-\mathrm{SiC}$ ultra high temperature ceramics under simulated atmospheric reentry conditions. Compos Sci Technol.2008;68:1718-1726.

7. Wuchina E, Opila E, Opeka M, Fahrenholtz W, Talmy I. UHTCs: ultra-high temperature ceramic materials for extreme environment applications. Electrochem Soc Interface. 2007;16:30.

8. Monteverde F, Bellosi A, Scatteia L. Processing and properties of ultra-high temperature ceramics for space applications. Mater Sci Eng, A. 2008;485:415-421.

9. Fahrenholtz WG, Hilmas GE, Talmy IG, Zaykoski JA. Refractory diborides of zirconium and hafnium. $J$ Am Ceram Soc. 2007;90:1347-1364.

10. Talmy IG, Zaykoski JA, Opeka MM. Synthesis, processing and properties of $\mathrm{TaC}-\mathrm{TaB}{ }_{2}-\mathrm{C}$ ceramics. J Eur Ceram Soc. 2010;30:2253-2263.

11. Han J, Hu P, Zhang X, Meng S, Han W. Oxidation-resistant $\mathrm{ZrB}_{2}-$ SiC composites at 2200 C. Compos Sci Technol. 2008;68:799806.

12. Padmavathi N, Ray K, Subrahmanyam J, Ghosal P, Sweety K. New route to process uni-directional carbon fiber reinforced $\left(\mathrm{SiC}+\mathrm{ZrB}_{2}\right)$ matrix mini-composites. J Mater Sci. 2009;44: 3255-3264.

13. Leslie CJ, Boakye E, Keller KA, Cinibulk MK. Development of continuous $\mathrm{SiC}$ fiber reinforced $\mathrm{HfB}_{2}-\mathrm{SiC}$ composites for aerospace applications. In: Bansal NP, Singh JP, Ko SW, Castro RHR, Pickrell G, Manjooran NJ, Nair KM, Singh G, eds. Processing and Propeties of Advanced Ceramics and Composites V, Vol. 240. Ceramic Transactions. Hoboken, NJ: John Wiley \& Sons; 2013:3-12.

14. Tang S, Deng J, Wang S, Liu W, Yang K. Ablation behaviors of ultra-high temperature ceramic composites. Mater Sci Eng, A. 2007;465:1-7.

15. Paul A, Jayaseelan DD, Venugopal S, et al. UHTC composites for hypersonic applications. Am Ceram Soc Bull. 2012;91:22-29.

16. Paul A, Venugopal S, Binner JGP, Vaidhyanathan B, Heaton ACJ, Brown PM. UHTC-carbon fibre composites: preparation, oxyacetylene torch testing and characterisation. J Eur Ceram Soc. 2013;33:423-432.

17. Jayaseelan DD, de Sa RG, Brown P, Lee WE. Reactive infiltration processing (RIP) of ultra high temperature ceramics (UHTC) into porous C/C composite tubes. J Eur Ceram Soc. 2011;31:361-368.

18. Zhao D, Zhang C, Hu H, Zhang Y. Ablation behavior and mechanism of 3D C/ZrC composite in oxyacetylene torch environment. Compos Sci Technol.2011;71:1392-1396.

19. Zhao D, Zhang C, Hu H, Zhang Y. Preparation and characterization of three-dimensional carbon fiber reinforced zirconium carbide composite by precursor infiltration and pyrolysis process. Ceram Int. 2011;37:2089-2093.

20. Wang Z, Dong S, Zhang X, et al. Fabrication and properties of Cf/SiC-ZrC composites. J Am Ceram Soc. 2008;91:3434-3436.

21. Li Q, Dong S, Wang Z, et al. Fabrication and properties of 3-D $\mathrm{Cf} / \mathrm{SiC}-\mathrm{ZrC}$ composites, using $\mathrm{ZrC}$ precursor and polycarbosilane. J Am Ceram Soc. 2012;95:1216-1219.

22. Sayir A. Carbon fiber reinforced hafnium carbide composite. $J$ Mater Sci. 2004;39:5995-6003.

23. Patterson MCL, He S, Fehrenbacher LL, Hanigofsky J, Reed BD. Advanced HfC-TaC oxidation resistant composite rocket thruster. Mater Manuf Processes. 1996;11:367-379.

24. Patterson MCL. Oxidation resistant HfC-TaC rocket thruster for high performance propellants, Vol. NAS3-27272; 1999:1-24.

25. Zou L, Wali N, Yang J-M, Bansal NP. Microstructural development of a Cf/ZrC composite manufactured by reactive melt infiltration. J Eur Ceram Soc. 2010;30:1527-1535.

26. Zhu Y, Wang S, Li W, Zhang S, Chen Z. Preparation of carbon fiber-reinforced zirconium carbide matrix composites by reactive melt infiltration at relative low temperature. Scripta Mater. 2012;67:822-825.

27. Wang Y, Liu W, Cheng L, Zhang L. Preparation and properties of $2 \mathrm{D} \mathrm{C} / \mathrm{ZrB}_{2}-\mathrm{SiC}$ ultra high temperature ceramic composites. Special Topic Section: Probing Strains and Dislocation Gradients With Diffraction. 2009;524:129-133.

28. Li L, Wang Y, Cheng L, Zhang L. Preparation and properties of 2D C/SiC-ZrB 2 -TaC composites. Ceram Int. 2011;37:891-896.

29. Hu H, Wang Q, Chen Z, Zhang C, Zhang Y, Wang J. Preparation and characterization of $\mathrm{C} / \mathrm{SiC}-\mathrm{ZrB}_{2}$ composites by precursor infiltration and pyrolysis process. Ceram Int. 2010;36:1011-1016.

30. Yang F, Zhang X, Han J, Du S. Characterization of hot-pressed short carbon fiber reinforced $\mathrm{ZrB}_{2}-\mathrm{SiC}$ ultra-high temperature ceramic composites. J Alloy Compd. 2009;472:395-399.

31. Musa C, Orru R, Sciti D, Silvestroni L, Cao G. Synthesis, consolidation and characterization of monolithic and $\mathrm{SiC}$ whiskers reinforced $\mathrm{HfB}_{2}$ ceramics. J Eur Ceram Soc. 2013;33:603-614.

32. Silvestroni L, Sciti D, Melandri C, Guicciardi S. Toughened $\mathrm{ZrB}_{2}$-based ceramics through $\mathrm{SiC}$ whisker or $\mathrm{SiC}$ chopped fiber additions. Special Issue: Aerospace Materials for Extreme Environments. 2010;30:2155-2164.

33. Zhang P, Hu P, Zhang X, Han J, Meng S. Processing and characterization of $\mathrm{ZrB}_{2}-\mathrm{SiCW}$ ultra-high temperature ceramics. $J$ Alloy Compd. 2009;472:358-362.

34. Zhang X, Xu L, Du S, Liu C, Han J, Han W. Spark plasma sintering and hot pressing of $\mathrm{ZrB}_{2}-\mathrm{SiCW}$ ultra-high temperature ceramics. J Alloy Compd. 2008;466:241-245.

35. Zhang X, Xu L, Du S, Han J, Hu P, Han W. Fabrication and mechanical properties of $\mathrm{ZrB}_{2}-\mathrm{SiCw}$ ceramic matrix composite. Mater Lett. 2008;62:1058-1060. 
36. Gasch M, Ellerby D, Johnson S. Handbook of Ceramic Composites. New York: Springer US; 2005:197-224.

37. Levine SR, Opila EJ, Robinson RC, Lorincz JA. Characterization of an Ultra-High Temperature Ceramic Composite, Vol. NASA TM-2004-213085. NASA technical report; 2004:1-26.

38. Sambell RAJ, Bowen DH, Phillips DC. Carbon fibre composites with ceramic and glass matrices. J Mater Sci. 1972;7:663-675.

39. Baxter RI, Rawlings RD, Iwashita N, Sawada Y. Effect of chemical vapor infiltration on erosion and thermal properties of porous carbon/carbon composite thermal insulation. Carbon. 2000;38: 441-449.

40. Ruh R, Garrett HJ, Domagala RF, Tallan NM. The Systern zirconia-hafnia. J Am Ceram Soc. 1968;51:23-28.

41. Courtright EL, Prater JT, Holcomb GR, Pierre GRS, Rapp RA. Oxidation of hafnium carbide and hafnium carbide with additions of tantalum and praseodymium. Oxid Met. 1991;36:423-437.

42. Paul A, Binner JGP, Vaidhyanathan B, Heaton ACJ, Brown PM. Oxyacetylene torch testing and microstructural characterization of tantalum carbide. J Microsc. 2013;250:122-129.
43. Savino R, De Stefano Fumo M, Sylvestroni L, Sciti D. Arc Jet testing on $\mathrm{HfB}_{2}$ and $\mathrm{HfC}$-based ultra high temperature ceramic materials. J Eur Ceram Soc. 2008;28:1899-1907.

44. Jacobson NS, Curry DM. Oxidation microstructure studies of reinforced carbon/carbon. Carbon. 2006;44:1142-1150.

How to cite this article: Paul A, Rubio V, Binner J, Vaidhyanathan B, Heaton A, Brown P. Evaluation of the high temperature performance of $\mathrm{HfB}_{2}$ UHTC particulate filled $\mathrm{C}_{\mathrm{f}} / \mathrm{C}$ composites. Int J Appl Ceram Technol. 2017;14:344-353. https://doi.org/10.1111/ ijac. 12659 